\title{
Manipulation of photoperiod in growth factors of beluga sturgeon Huso huso
}

\author{
M. R. Ghomi ${ }^{1 *}$, R. M. Nazari ${ }^{2}$, M. Sohrabnejad ${ }^{3}$, M. Ovissipour ${ }^{4}$, M. Zarei ${ }^{2}$, A. Esmaili Mola ${ }^{2}$, C. \\ Makhdoomi $^{2}$, A. Rahimian ${ }^{2}$, H. Noori ${ }^{2}$ and A. Naghavi ${ }^{2}$ \\ ${ }^{1}$ Department of Fisheries Sciences, Islamic Azad University of Tonekabon, 46817, Tonekabon, Iran. \\ ${ }^{2}$ Rajaei Sturgeon Fish Farm, P.O. Box: 833, Sari, Iran. \\ ${ }^{3}$ Department of Fisheries Sceinces, Tarbiat Modarres University, Noor, Iran. \\ ${ }^{4}$ Faculty of Fisheries Sciences, Gorgan Agricultural Sciences and Natural Resources University, Gorgan, Iran.
}

Accepted 7 January, 2010

\begin{abstract}
The beluga sturgeon is considered as the most important species for caviar production. This study aimed to evaluate effects of photoperiod manipulation on growth factors of beluga sturgeon. The six photoperiod regimes (light: dark cycle) including natural photoperiod (control), 24L : 0D, 16L : 8D, 12L : 12D, 8L : 16D and 0L : 24D with the three replicates. The treatment 5 (8L: 16D) gained the greatest final weight $(2194.4 \mathrm{~g})$ after 73 rearing days and besides, the treatments 4,3 and 1 (12L: 12D, 16L : 8D, and Control) can be considered as the good photoperiod regimes for beluga sturgeon. The continuous light (24L : $0 D)$ and continuous dark $(0 \mathrm{~L}: 24 \mathrm{D})$ significantly $(P<0.05)$ reduced the final weight of fish to $1804.2 \mathrm{~g}$ and $1976.1 \mathrm{~g}$, respectively. Regulated photoperiod significantly improve growth rate and food conversion ratio of beluga sturgeon.
\end{abstract}

Key words: Beluga sturgeon, Huso huso, growth factors, photoperiod.

\section{INTRODUCTION}

The family Acipenseridae is comprised of four genera and 27 species. Almost all sturgeon species are endangered in recent decades. Sturgeon populations have suffered from overfishing, loss of habitat, and the deterioration of water quality (May et al., 1997; Kynard, 1997). Sturgeons are particularly long-lived animals (up to 100 years in the wild) that take 5-30 years to reach sexual maturity and after the first sexual maturity, maturation and spawning occurs every 2-4 years (Billard and Lecointre, 2001). However, stocks of sturgeons are decreasing dramatically (Ronyai and Varadi, 1995), the total sturgeon catches and caviar production in Iran in 1993 was 1710 and $106 \mathrm{t}$, while in 2006 it decreased to 330 and $31.3 \mathrm{t}$, respectively (IFO, 2007). Sturgeon culture can provide an alternative source of meat and caviar in addition to wild stocks.

\footnotetext{
${ }^{*}$ Corresponding author. E-mail: mghomi@tonekabon.iau.ac.ir.
}

Abbreviations: SGR, Specific growth rate; FCR, feed conversion ratio; L, light regime or photoperiod; D, dark period; SD, standard deviation; SEM, standard error of mean.
Environmental and nutritional factors as well as genetic notably influence fish growth. In addition to temperature, photoperiod is an important factor that affects living organisms including fishes. Effects of photoperiod on growth rate and other variables has been studied in various species (Saunders and Harmon, 1988; Krakenes et al., 1991; Imsland et al., 1995; Davis et al., 1999; Jonassen et al., 2000; Kissil et al., 2001; Petit et al., 2003; Trippel and Neil, 2003; Norberg et al., 2004; Bayarri et al., 2004; Blancas-Arroyo et al., 2004; Taylor et al., 2006; Valenzuela et al., 2006; Bonnet et al., 2007; Ruchin, 2007). Very little information exists regarding effects of photoperiods on growth of beluga Huso huso, especially considering the species is the most commonly cultured sturgeon in Iran and its caviar as the most expensive product in the world. The objective of the present study was to examine the growth responsiveness of beluga sturgeon to photoperiod manipulation.

\section{MATERIALS AND METHODS}

Fish were obtained from artificially spawned broodstocks collected from Marjani sturgeon fish farm (Gorgan, Iran) and then transported 


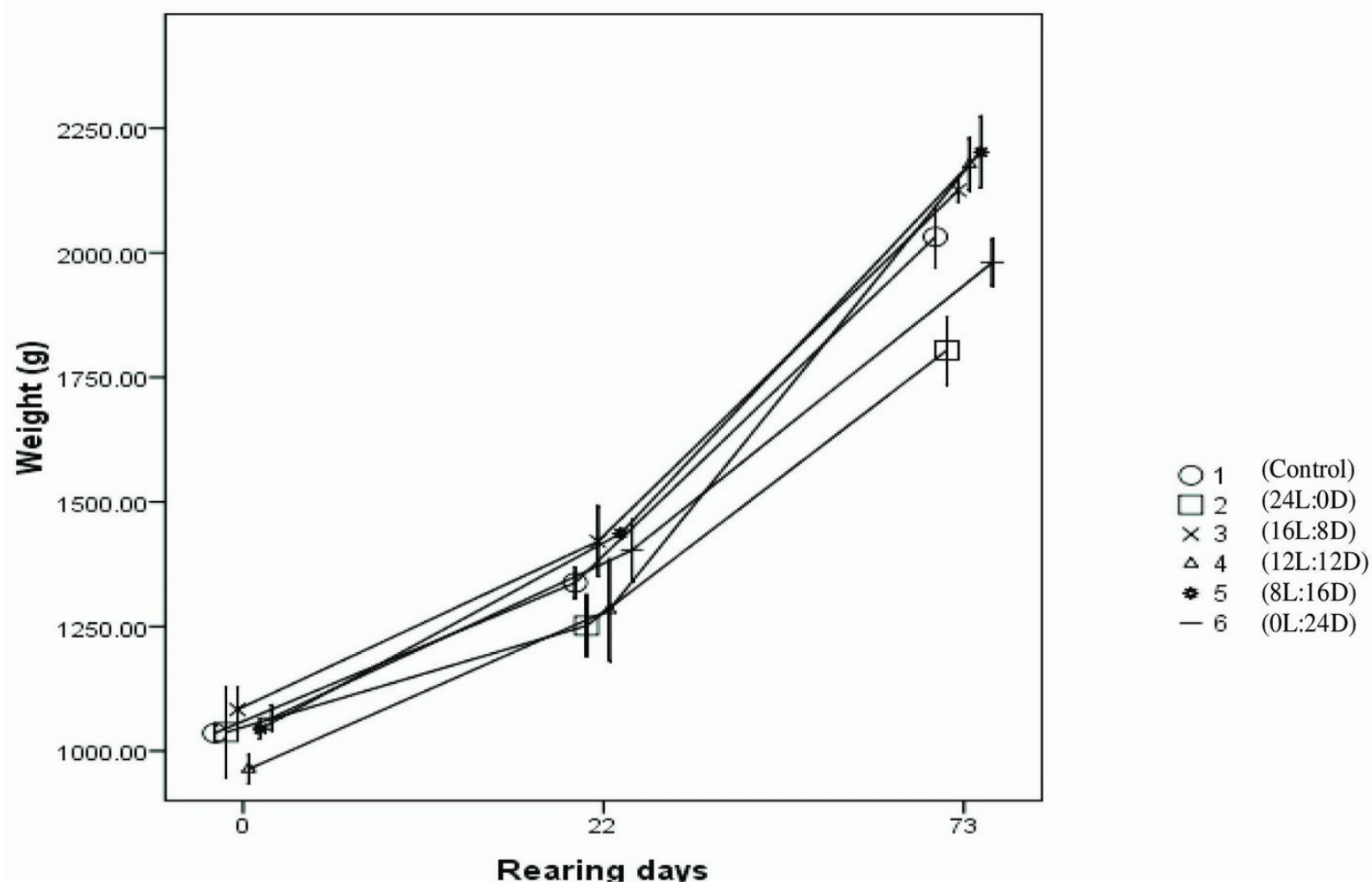

Figure 1. Weight of beluga sturgeon in all photoperiod treatments in rearing days (Error bars show SEM).

to Rajaee sturgeon fish farm, Sari, Iran. The experiment commenced in June, 2009, when the fish were 24 months old with a mean weight of $1038 \mathrm{~g}$ (range, $866-1166 \mathrm{~g}$ ) and reached a mean weight of $2043 \mathrm{~g}$ (range, $1070-2975 \mathrm{~g}$ ) after 73 days rearing period. Mean total length in the beginning of study was $61.5 \mathrm{~cm}$ (range, $57-65 \mathrm{~cm})$ and finally increased to $71.1 \mathrm{~cm}(63-79 \mathrm{~cm})$ at the end of experiment.

The eighteen tanks $(2 \times 2 \times 0.40 \mathrm{~m}$, water volume: $1600-\mathrm{I})$ were located in Sari sturgeon fish farm, Iran. Each tank was stocked with 6 fishes and a total of 108 fishes were used in this study. Water inlet was about $10 \mathrm{~L} / \mathrm{min}$ and all tanks were washed everyday. Fish were fed with Chine Co. (Tehran, Iran) pellet feed (36\% protein, $14 \%$ fat, $20 \%$ carbohydrate, $10 \%$ ash, $4 \%$ fiber, $11 \%$ moisture) by $2 \%$ of body weight with the three times interval per day.

Throughout the experiment, water temperatures and $\mathrm{pH}$ in the tanks ranged from $21-25^{\circ} \mathrm{C}$ and $7.9-8.3$, respectively. Dissolved oxygen levels ranged between 6.0 and $8.5 \mathrm{mg} / \mathrm{L}$, with most recorded values higher than $7 \mathrm{mg} / \mathrm{L}$. The water source was free of ammonia and nitrite.

All the fishes were acclimatized for a week under a manipulated photoperiod regimes. Fish received the six photoperiod regimes (light: dark cycle) including: natural photoperiod (control), 24L : 0D, $16 \mathrm{~L}: 8 \mathrm{D}, 12 \mathrm{~L}: 12 \mathrm{D}, 8 \mathrm{~L}: 16 \mathrm{D}$, and $\mathrm{OL}: 24 \mathrm{D}$ by the three replications (tanks). The fifteen manipulated photoperiod tanks were covered by black nylon screens and the daylight lamps placed $1 \mathrm{~m}$ above tanks with controlling digital timers.

A random sample of three individuals per tank was taken in each biometric time for measuring the biometrical data. Specific growth rate (SGR) was calculated as (In final weight-In initial weight)/duration of experiment (days). Feed conversion ratio (FCR) was measured by (feed intake/body weight gain). The differences between groups were analyzed by using one-way ANOVA and Duncan's multiple range tests at $P<0.05$.

\section{RESULTS AND DISCUSSION}

Weight and total length of beluga sturgeon in all photoperiod treatments during rearing days are shown in Figures 1 and 2. Continuous light in treatment 2 (24L : OD) caused a significant reduction in weight and total length of fish in days 22 and 73. Other photoperiod regimes including 16L: 8D, 12L: 12D, 8L: 16D, and natural photoperiod (control) showed an appropriate result in weight and total length.

Growth factors in all photoperiod regimes were compared in Table 1. The treatment 5 (8L: 16D) gained greatest final weight $(2194.4 \mathrm{~g})$ after 73 rearing days and also, the treatments 4,3 and 1 (12L: $12 \mathrm{D}, 16 \mathrm{~L}: 8 \mathrm{D}$, and Control) can be considered as the best photoperiod regimes for beluga sturgeon. The continuous light in treatment $2(24 \mathrm{~L}: 0 \mathrm{D})$ significantly $(\mathrm{P}<0.05)$ reduced the final weight of fish to $1804.2 \mathrm{~g}$. The continuous dark at treatment 6 (OL: 24D) caused a similar reduction (1976.1 g) in final weight of fish $(P<0.05)$. Thus, culture of beluga sturgeon in both continuous light and dark is not compatible with the physiological condition of this species and result in a significant reduction in growth rate. Semenkova and Trenkler (1993) pointed out that mean weight of 4 month old beluga sturgeon $H$. huso exposed to a $24 \mathrm{~h}$ photoperiod was by $15 \%$ lower compared to a $16 \mathrm{~h}$ photoperiod, which was in accordance with our findings. On the contrary, Askarian and Kousha (2009) 


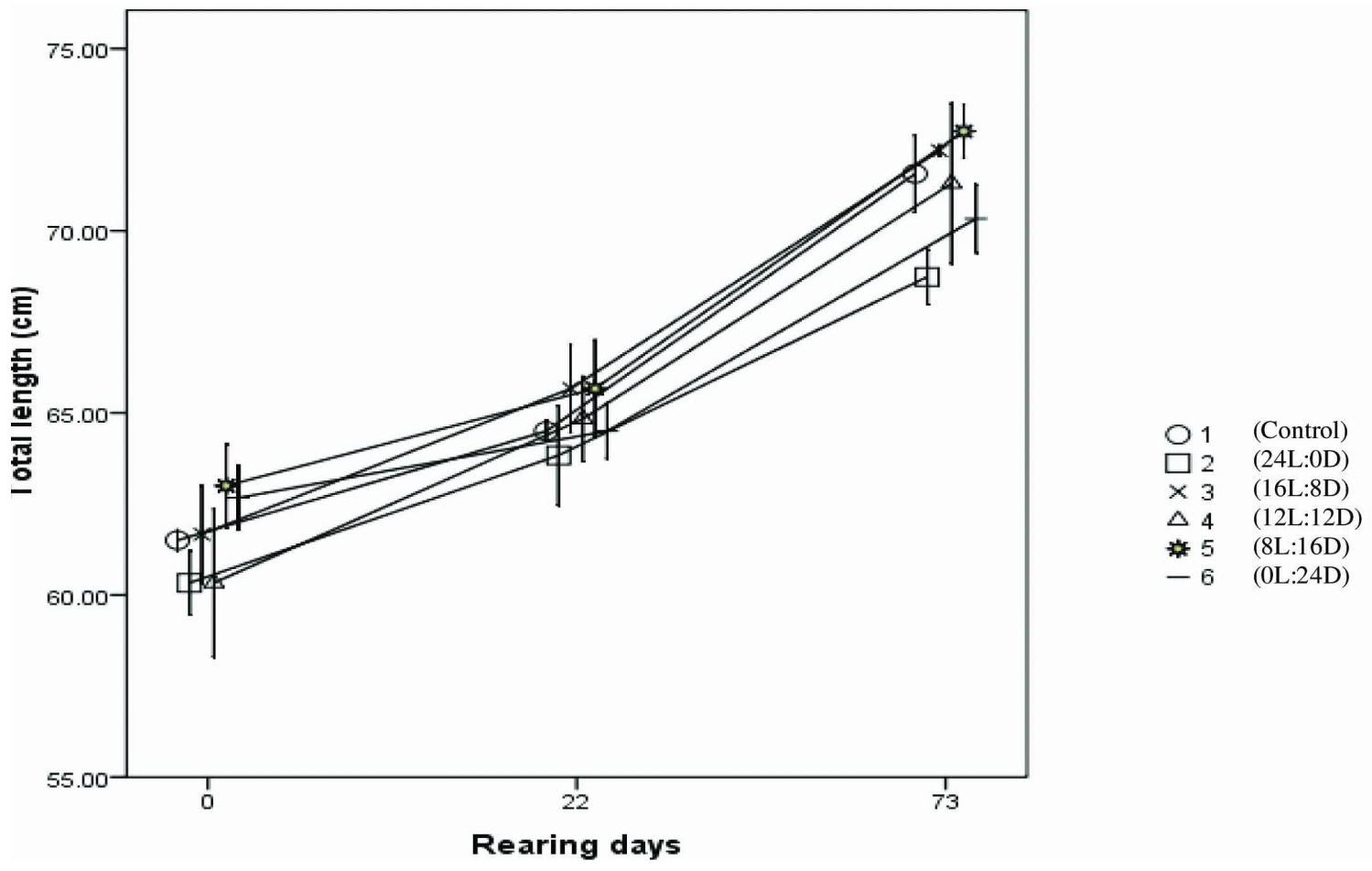

Figure 2. Total length of beluga sturgeon in all photoperiod treatments in rearing days (Error bars show SEM).

Table 1. Growth factors of beluga sturgeon in all photoperiod treatments. Data were presented as mean \pm SD.

\begin{tabular}{|l|c|c|c|c|c|c|}
\hline $\begin{array}{c}\text { Photoperiod } \\
\text { treatments }\end{array}$ & $\begin{array}{c}\text { Initial total } \\
\text { length }(\mathbf{c m})\end{array}$ & $\begin{array}{c}\text { Initial weight } \\
(\mathbf{g})\end{array}$ & $\begin{array}{c}\text { Final weight } \\
(\mathbf{g})\end{array}$ & $\begin{array}{c}\text { Final total length } \\
(\mathbf{c m})\end{array}$ & $\begin{array}{c}\text { SGR } \\
(\%)\end{array}$ & FCR \\
\hline$(1)$ Control & $61.50 \pm 0.5$ & $1036.06 \pm 26.7$ & $2032.6 \pm 342.0^{\mathrm{a}^{*}}$ & $71.52 \pm 3.4^{\mathrm{ab}}$ & $0.91 \pm 0.04^{\mathrm{abc}}$ & $1.68 \pm 0.14^{\mathrm{b}}$ \\
$(2) 24 \mathrm{~L}: 0 \mathrm{D}$ & $60.33 \pm 1.5$ & $1037.73 \pm 154.4$ & $1804.2 \pm 351.0^{\mathrm{b}}$ & $68.77 \pm 2.7^{\mathrm{c}}$ & $0.78 \pm 0.17^{\mathrm{c}}$ & $2.17 \pm 0.40^{\mathrm{a}}$ \\
$(3) 16 \mathrm{~L}: 8 \mathrm{D}$ & $61.66 \pm 2.3$ & $1083.33 \pm 76.3$ & $2125.5 \pm 255.0^{\mathrm{a}}$ & $72.22 \pm 2.5^{\mathrm{ab}}$ & $0.92 \pm 0.10^{\mathrm{abc}}$ & $1.58 \pm 0.12^{\mathrm{b}}$ \\
$(4) 12 \mathrm{~L}: 12 \mathrm{D}$ & $60.33 \pm 3.5$ & $963.83 \pm 50.2$ & $2177.9 \pm 311.8^{\mathrm{a}}$ & $71.33 \pm 3.1^{\mathrm{ab}}$ & $1.08 \pm 0.01^{\mathrm{a}}$ & $1.40 \pm 0.04^{\mathrm{b}}$ \\
$(5) 8 \mathrm{~L}: 16 \mathrm{D}$ & $63.00 \pm 2.0$ & $1044.40 \pm 34.0$ & $2194.4 \pm 237.4^{\mathrm{a}}$ & $72.70 \pm 3.0^{\mathrm{a}}$ & $1.01 \pm 0.10^{\mathrm{ab}}$ & $1.45 \pm 0.17^{\mathrm{b}}$ \\
$(6)$ L : 24D & $62.66 \pm 1.5$ & $1066.63 \pm 44.1$ & $1976.1 \pm 215.6^{\mathrm{ab}}$ & $70.29 \pm 2.9^{\mathrm{bc}}$ & $0.84 \pm 0.11^{\mathrm{bc}}$ & $1.84 \pm 0.25^{\mathrm{ab}}$ \\
\hline
\end{tabular}

${ }^{1}$ Natural photoperiod. *Mean values with the same letter for each column are not significantly different $(P>0.05)$.

showed that fish in exposure of continuous light (24L: OD) has gained the highest weight $(916.61 \mathrm{~g})$, highest SGR (0.87) and the lowest FCR (1.5) among other photoperiod regimes.

Other sturgeon species showed different results. The highest growth rate of Acipenser nudiventris was observed under a $24 \mathrm{~h}$ photoperiod (Ponomarenko et al., 1992). Kryuchkov and Obukhov (2006) studied the effect of photoperiod on the development of starlet Acipenser ruthenus and the weight of the fish exposed to $24 \mathrm{~h}$ photoperiod was $39 \%$ higher compared to control and the absence of light decreased the fish weight by $33 \%$. The maximum growth rate of juvenile Siberian sturgeon, Acipenser baerii was in 12, 16, and $24 \mathrm{~h}$ photoperiod (Ruchin, 2007). The exposure to darkness significantly decreased this index by $7.8-18.5 \%$ and under continuous illumination, this index insignificantly increased relative to control (Ruchin, 2007).

The maximum specific growth rate (SGR) has been observed by an intermediate light/dark cycle (12L: 12D) with significant difference $(P<0.05)$ with other light conditions (Table 1). This photoperiodic regime showed a lowest feed conversion ratio (FCR, 1.40) among others, however, the treatment 5 (8L: 16D) has had the nearest values for SGR and FCR to this treatment. By contrast, the lowest SGR (0.78) and highest FCR (2.17) have been presented by the fish under continuous light (24L: OD) (Table 1). The highest growth rate and food utilization efficiency in Pagrus pagrus were recorded under $12 \mathrm{~h}$ photoperiod, while the negative growth was observed in the dark (Pavlidis et al., 1999). The highest weight gain for European eel observed under $12 \mathrm{~h}$ light/dark regime 
and decreased food coefficient in the dark (Meske, 1982).

The optimal light conditions increased the total food consumption and conversion by $5.0-20.3 \%$ and 11.7 $12.5 \%$, respectively, for juvenile Siberian sturgeon (Ruchin, 2007). As a result, regulated photoperiod significantly improve growth rate and food conversion ratio of beluga sturgeon.

\section{ACKNOWLEDGEMENT}

We wish to thank the operational staff of Rajaee sturgeon fish farm, Sari, Iran.

\section{REFERENCES}

Askarian F, Kousha A (2009). The influence of photoperiod on farming of beluga sturgeon (Huso huso): Evaluation by growth and health parameters in serum. J. Fish. Aquat. Sci. 4(1): 41-49.

Bayarri MJ, Rodriguez L, Zanuy S, Madrid JA, Sanchez-Vazquez FJ, Kagawa H, Okuzawa K, Carrillob M (2004). Effect of photoperiod manipulation on the daily rhythms of melatonin and reproductive hormones in caged European sea bass (Dicentrarchus labrax). Gen. Comp. Endocrin. 136: 72-81.

Blancas-Arroyoa GL, Figueroa-Lucerob G, Barriga-Sosaa IA, Arredondo-Figueroa JL (2004). Effects of an artificial photothermal cycle on the reproduction of the shortfin silverside, Chirostoma humboldtianum, Valenciennes, 1835 (Pisces: Atherinopsidae). Aquaculture, 241: 575-585.

Billard R, Lecointre G (2001). Biology and conservation of sturgeon and paddle fish. Rev. Fish Biol. Fish. 10: 355-392.

Bonnet E, Montfort J, Esquerre D, Hugot K, Fostier A, Bobe J (2007). Effect of photoperiod manipulation on rainbow trout (Oncorhynchus mykiss) egg quality: A genomic study. Aquaculture, 268: 13-22.

Davis B, Bromage NR, Swanson P (1999). The brain-pituitarygonadal axis of female rainbow trout, Oncorhynchus mykiss: effects of photoperiod manipulation. Gen. Comp. Endocrinol. 115: 155-166.

IFO (2007). Production reports of Iran fisheries organization. Iran Fisheries Organization, Tehran, Iran.

Imsland AK, Folkvord A, Stefansson SO, (1995). Growth, oxygen consumption and activity of juvenile turbot (Scopthalmus maximus L.) reared under different temperatures and photoperiods. Neth. J. Sea Res. 34: 149-159.

Jonassen TM, Imsland AK, Kadowaki S, Stefabsson SO (2000). Interaction of temperature and photoperiod on growth of Atlantic halibut Hippoglossus hippoglossus L. Aquact. Res. 31: 219-227.

Kissil GW, Lupatsch I, Elizur A, Zohar Y (2001). Long photoperiod delayed spawning and increased somatic growth in gilthead sea bream (Sparus aurata). Aquaculture, 200: 363-379.

Krakenes R, Hansen T, Stefansson SO, Taranger GL (1991). Continuous light increases growth rate of Atlantic salmon (Salmo salar L.) postsmolts in sea cages. Aquaculture, 95: 281-287.
Kryuchkov VI, Obukhov DK (2006). Development of Juvenile Sterlet Acipenser ruthenus L. Reared under Different Light Conditions, in Akvakul'tura osetrovykh ryb: dostizheniya i perspektivy razvitiya (Sturgeon Pisciculture: Advancements and Outlooks), Moscow: VNIRO, pp. 27-29.

Kynard B (1997). Life history, latitudinal patterns, and status of the shortnose sturgeon, Acipenser brevirostrum. Environ. Biol. Fish. 48: 319-334.

May B, Krueger CC, Kincaid HL (1997). Genetic variation at microsatellite loci in sturgeon: primer sequence homology in Acipenser and Scaphirhynchus. Can. J. Fish. Aquat. Sci. 54: 15421547.

Meske C (1982). Futterung von Aalen in Dunkeln. Inf. Fishwirt, 29: 136138.

Norberg B, Brownb CL, Halldorssonc O, Stenslandd K, Bjornssone BT (2004). Photoperiod regulates the timing of sexual maturation, spawning, sex steroid and thyroid hormone profiles in the Atlantic cod (Gadus morhua). Aquaculture, 229: 451-467.

Pavlidis M, Paspatis M, Koistinen M (1999). Diel Rhythms of Serum Metabolites and Thyroid Hormones in Red Porgy Held in Different Photoperiod Regimes. Aquat. Intel. 7: 29-44.

Petit G, Beauchaud M, Attia J, Buisson B (2003). Food intake and growth of largemouth bass (Micropterus salmoides) held under alternated light/dark cycle (12L: 12D) or exposed to continuous light. Aquaculture, 228: 397-401.

Ponomarenko VV, Kryuchkov VI, Marshin VG (1992). Effect of the Light Factor on the Behavior, Nervous System Excitability, and Growth Rate of the Ship in: 8-ya Nauch. konf. po ekol. fiziologii i biokhimii ryb, Petrozavodsk. Int. Sci. Conf. Fish Ecol. Physiol. Biochem. pp. 46-47.

Ronyai A, Varadi L (1995). The sturgeons. In: Reproduction of Aquatic Animals: Fishes, (eds. by Nash CE \& Novotny AJ), World Animal Sciences C8. Amsterdam, Elsevier. pp. 95-108.

Ruchin AB (2007). Effect of Photoperiod on Growth, Physiological and Hematological Indices of Juvenile Siberian Sturgeon Acipenser baerii. Biol. Bull. 34(6): 583-589.

Saunders RL, Harmon PR (1988). Extended daylength increases postsmolt growth of Atlantic salmon. World Aquat. 19: 72-73.

Semenkova TB, Trenkler IV (1993). Effects of Photoperiod, Epiphysectomy and Pharmacological Preparations on Growth Rate and Metabolism in Young Sturgeons, Int. Symp. on Sturgeons: Abstr. Bull. Moscow. pp. 13-14.

Taylor JF, North BP, Porter MJR, Bromage NR, Migaud H (2006). Photoperiod can be used to enhance growth and improve feeding efficiency in farmed rainbow trout, Oncorhynchus mykiss. Aquaculture, 256: 216-234.

Trippel EA, Neil SRE (2003). Effects of photoperiod and light intensity on growth and activity of juvenile haddock (Melanogrammus aeglefinus). Aquaculture, 217: 633-645.

Valenzuela AE, Silva VM, Klempau AE (2006). Qualitative and quantitative effects of constant light photoperiod on rainbow trout (Oncorhynchus mykiss) peripheral blood erythrocytes. Aquaculture, 251: 596-602. 